\title{
Course of COPD Assessment Test (CAT) Scores During Bacterial Exacerbations of Chronic Obstructive Pulmonary Disease Treated in Outpatient Setting
} \author{
Saso Stoleski ${ }^{1}$ and Dragan Mijakoski ${ }^{1}$ \\ ${ }^{I}$ Institute for Occupational Health of R. Macedonia, R. Macedonia \\ ${ }^{2}$ Institute for Epidemiology and Biostatistics, Skopje, R. Macedonia
}

Jordan Minov $^{*}, 1$, Jovanka Karadzinska-Bislimovska ${ }^{1}$, Kristin Vasilevska ${ }^{2}$,

\begin{abstract}
Introduction: COPD Assessment Test (CAT) is an 8-items questionnaire for assessment of health status in patients with chronic obstructive pulmonary disease (COPD).

Objective: To evaluate the course of CAT scores during bacterial exacerbations of COPD treated in outpatient setting.

Methods: We performed an observational, prospective study including 81 outpatients (57 males and 24 females, aged 43 to 74 years) with bacterial exacerbation of COPD. All participants completed CAT at initial visit (i.e. at the time of diagnosis of exacerbation and beginning of its treatment), 10 and 30 days after initial visit. Mean scores of each item, as well as the overall mean score, at these time points were compared.

Results: The mean scores for each CAT question at initial visit varied from 2.6 to 3.5, whereas the mean scores for each CAT question 10 days after initial visit varied from 1.7 to 2.6. We registered significant reduction of the mean overall CAT score 10 days after initial visit as compared to its value at initial visit of $6.9 \pm 2.7$ points $(16.8 v s 23.7 ; P<0.001)$. The mean scores for each CAT question 30 days after initial visit varied from 1.3 to 2.4. We registered reduction of mean overall CAT score 30 days after initial visit as compared to its score 10 days after initial visit of $2.9 \pm 1.2$ points (13.9 vs 16.8; $P<0.005)$. The mean overall CAT score 30 days after initial visit was reduced for $9.8 \pm 4.5$ points as compared to its value at initial visit $(13.9$ vs $23.7 ; P<0.001)$.

Conclusion: We found significant improvement in the patient's health status during recovery from exacerbation as compared to their health status at the time of exacerbation confirming the CAT as an effective tool to measure health status in patients with COPD.
\end{abstract}

Keywords: Chronic obstructive pulmonary disease, exacerbation, health status, questionnaire, score.

\section{INTRODUCTION}

Chronic obstructive pulmonary disease (COPD) remains a frequent disease associated with significant economic burden. In the European Union, the total direct costs of respiratory disease are estimated to be about $6 \%$ of the total health care budget, with COPD accounting for more than a half of this cost (38,6 billion Euros) [1].

In order to guide therapy, the patients with stable COPD are assessed and classified in 4 groups (A, B, C, and D) by combined COPD assessment. This assessment considers separately following aspects of the disease: current level of patient's symptoms, severity of the spirometric abnormality, exacerbation risk, and presence of comorbidities. The most comprehensive questionnaires used in routine practice for assessment of the symptoms and the patient's health status

*Address correspondence to this author at the Department of Cardiorespiratory Functional Diagnostics, Institute for Occupational Health of R. Macedonia - WHO Collaborating Center and GA ${ }^{2}$ LEN Collaborating Center, II Makedonska Brigada 43, 1000 Skopje, R. Macedonia;

Tel: + 38922639 637; Fax: + 38922621 428; E-mail: minovj@hotmail.com are COPD Assessment Test (CAT) and COPD Control Questionnaire (CCQ) [2]. CAT is an 8-items unidimensional questionnaire of health status impairment in COPD patients. It was developed to be applicable worldwide, validated translations are available in many languages, and its usefulness is documented in several studies [3].

The course of COPD can be affected by acute events characterized by a worsening of the patient's respiratory symptoms that is beyond normal day-to-day variations and leads to a change in medications, known as exacerbations [2]. COPD exacerbations have serious negative impact on patient quality of life, lung function, and socioeconomic costs so their prevention, early detection, and prompt treatment have a great importance in the management of the disease. Despite treatment with maintenance medications, COPD patients continue to have exacerbations, so new medications and disease management interventions are warranted to reduce the severity and frequency of exacerbations and the related cost impact of the disease [4].

Respiratory infections account for up to $80 \%$ of exacerbations, of which bacterial infections are involved in 
around 50-70\% [5]. The criteria of Anthonisen (i.e. increase in baseline dyspnea, cough, and/or sputum production) [6] are still the most important classification system to identify patients likely to be infected with bacterial pathogens based on presentation of clinical symptoms [7, 8]. According to the actual version of the Global Initiative for Chronic Obstructive Pulmonary Disease (GOLD) [2], antibiotics should be given to patients with type I exacerbation (presence of all three symptoms), with type II exacerbation (presence of two symptoms if increased purulence of sputum is one of them), as well as in patients who require mechanical ventilation (invasive or noninvasive). Depending on the severity of an exacerbation and/or the severity of the underlying disease, an exacerbation can be managed in an outpatient or inpatient setting. More than $80 \%$ of exacerbations can be ambulatory treated with bronchodilators, antibiotics and corticosteroids [9]. Severe COPD exacerbations are managed in the hospital, potential indications for hospital assessment or admission are given in the actual GOLD version [2]. Research studies have shown that it may take several weeks for patients to recover from a single moderate-severe exacerbation and some patients may never recover fully [10].

The aim of the present study is to evaluate the course of CAT scores during bacterial exacerbations of COPD treated in outpatient setting.

\section{MATERIALS AND METHODOLOGY}

\section{Study Design}

An observational, prospective study was performed at the Institute for Occupational Health of R. Macedonia, Skopje WHO Collaborating Center and $\mathrm{GA}^{2} \mathrm{LEN}$ Collaborating Center in the period November 2013-May 2014. The CAT scores of COPD patients with bacterial exacerbation treated in outpatient setting at initial visit were compared with the CAT scores of the same patients 10 and 30 days after initial visit.

\section{Study Population}

Patients of both genders, aged 43 to 74 years, were recruited in the study if they met the following inclusion criteria: patients with COPD demonstrated by spirometry performed in stable state with a post-bronchodilator forced expiratory volume in one second/force vital capacity (FEV1/FVC) ratio $<0.7$; smokers or ex-smokers of at least 10 pack-years smoked; patients with bacterial exacerbation defined according the Anthonisen criteria [6] and treated in outpatient setting according to the actual recommendations [2].

The exclusion criteria in the study were: patients with another respiratory disease (e.g. bronchial asthma, bronchiectasis, pneumonia, cystic fibrosis, etc.); bacterial exacerbations requiring hospital treatment; and patients who did not retain sufficient capacity for normal conduction of the study.

All participants were informed about the study and their written consent was obtained.

\section{Completion of the CAT}

All patients with bacterial exacerbation completed the CAT at initial visit (i.e. at the time of diagnosis of exacerbation and beginning of its treatment), 10 days after initial visit (i.e. at the time when treatment was ended) and 30 days after the initial visit.

The questionnaire consisted 8 original CAT items [11] translated in Macedonian:

\section{Q1 I never cough/I cough all the time}

Q2 I have no phlegm (mucus) in my chest at all/My chest is completely full of phlegm (mucus)

Q3 My chest does not feel tight at all/My chest feel very tight

Q4 When I walk up a hill or one flight of stairs I am not breathless/When I walk up a hill or one flight of stairs I am very breathless

Q5 I am not limited doing activities at home/I am very limited doing activities at home

Q6 I am confident leaving my home despite my lung condition/I am not at all confident leaving my home because of my lung condition

Q7 I sleep soundly/I don't sleep soundly because of my lung condition

Q8 I have lots of energy/I have no energy at all

Each question had score ranging from 0 to 5 points $(0=$ no impairment). The patients had to circle the appropriate point for each question at the time of exacerbation and at the time when the exacerbation was resolved (i.e. 4 to 6 weeks from the initial visit). An overall CAT score was derived as a sum of the scores for each response. It may range from 0 to 40 providing a measure of the impact of the disease on a patient's health status, i.e. of the impact of an exacerbation and recovery from an exacerbation on a patient's health status. The overall CAT scores more than 30 and more than 20 indicate very high and high impact of COPD on patient's health status, respectively. The overall CAT score ranging from 10 to 20 indicates medium impact, the overall CAT score less than 10 indicates low impact of the disease on the patient's health status, whereas the overall CAT score of 5 represents the upper limit of normal in healthy non-smokers [11].

\section{Statistical Analysis}

The quantitative variables were expressed as mean values with standard deviation (SD), whereas the qualitative variables as absolute frequencies and percentages. A comparison of the mean scores of the particular CAT questions, as well as the mean overall CAT scores was done by Student's t-test. A $P$-value less than 0.05 was considered as statistically significant. Statistical analysis was performed using the Statistical Package for the Social Sciences (SPSS) version 11.0 for Windows. 


\section{RESULTS}

From a total of 102 patients enrolled in the study 9 were lost to follow-up, 7 were excluded due to insufficient information for analysis and 5 were hospitalized in the first two or three days due to worsening of exacerbation, leaving 81 eligible participants.

The demographic and clinical characteristics of the study population are given in Table $\mathbf{1}$.

The mean scores for each CAT question at initial visit varied from 2.6 for $Q 7$ to 3.5 for $Q 1$, whereas the mean scores for each CAT question 10 days after initial visit varied from 1.7 for $Q 6$ to 2.6 for $Q 1$. Statistically significant reduction in the mean scores 10 days after initial visit as compared to the mean scores at initial visit was registered for all eight questions (Fig. 1).

We registered reduction of mean overall CAT score 10 days after initial visit as compared to its score at initial visit of $6.9 \pm 2.7$ points $(16.8$ vs 23.7; $P<0.001)$ (Fig. 2).

The mean scores for each CAT question 30 days after initial visit varied from 1.3 for $Q 6$ to 2.4 for $Q 1$. Statistically significant reduction in the mean scores 30 days after initial visit as compared to the mean scores 10 days after initial visit was registered for all eight questions (Fig. 3).

We registered reduction of mean overall CAT score 30 days after initial visit as compared to its score 10 days after initial visit of $2.9 \pm 1.2$ points $(13.9$ vs $16.8 ; P<0.005)$. The mean overall CAT score 30 days after initial visit was reduced for $9.8 \pm 4.5$ points as compared to its value at initial visit (13.9 vs 23.7; $P<0.001)$ (Fig. 4).
Table 1. Demographic and clinical characteristics of the study population.

\begin{tabular}{|c|c|}
\hline Variable & $\begin{array}{l}\text { Study Subjects } \\
\quad(\mathbf{n}=\mathbf{8 1})\end{array}$ \\
\hline Males & $57(70.4)$ \\
\hline Mean age (years) & $56.1 \pm 10.7$ \\
\hline Active smokers & $37(45.7)$ \\
\hline Ex-smokers & $44(54.3)$ \\
\hline Mean pack-years smoked & $18.6 \pm 5.7$ \\
\hline Exposed to ETS & $28(34.6)$ \\
\hline Mean BMI & $25.4 \pm 2.9$ \\
\hline Mean duration of & $7.3 \pm 3.1$ \\
\hline diagnosed COPD (years) & $60.3 \pm 7.8$ \\
\hline Mean $\mathrm{FEV}_{1}$ at initial visit (\% pred) & $64.2 \pm 6.2$ \\
\hline Mean $\mathrm{FEV}_{1} 30$ days after beginning of the treatment ( $\%$ pred) & \\
\hline Exacerbation in previous year & $1.8 \pm 0.7$ \\
\hline Comorbidities & \\
\hline Arterial hypertension & $22(27.2)$ \\
\hline Diabetes type 2 & $14(17.3)$ \\
\hline Ischemic heart disease & $10(12.3)$ \\
\hline
\end{tabular}

Data are presented as $\mathrm{n}$, mean $\pm \mathrm{SD}$, or $\mathrm{n}(\%)$.

BMI: body mass index; COPD: chronic obstructive pulmonary disease; $\mathrm{FEV}_{1}$ : forced expiratory volume in one second; $\%$ pred: $\%$ of predicted value; SD: standard deviation.

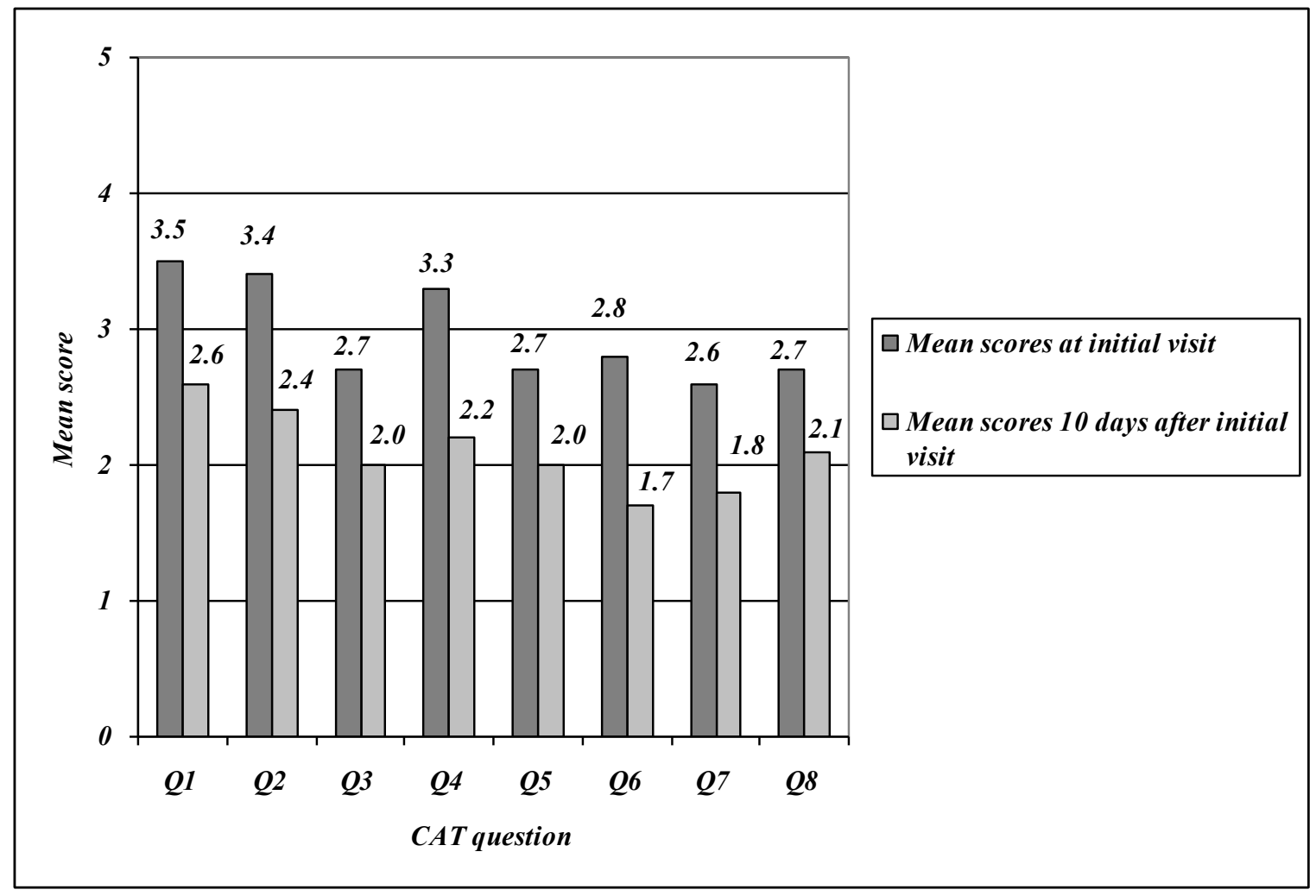

Fig. (1). Mean scores of the CAT questions at initial visit and 10 days after initial visit. 


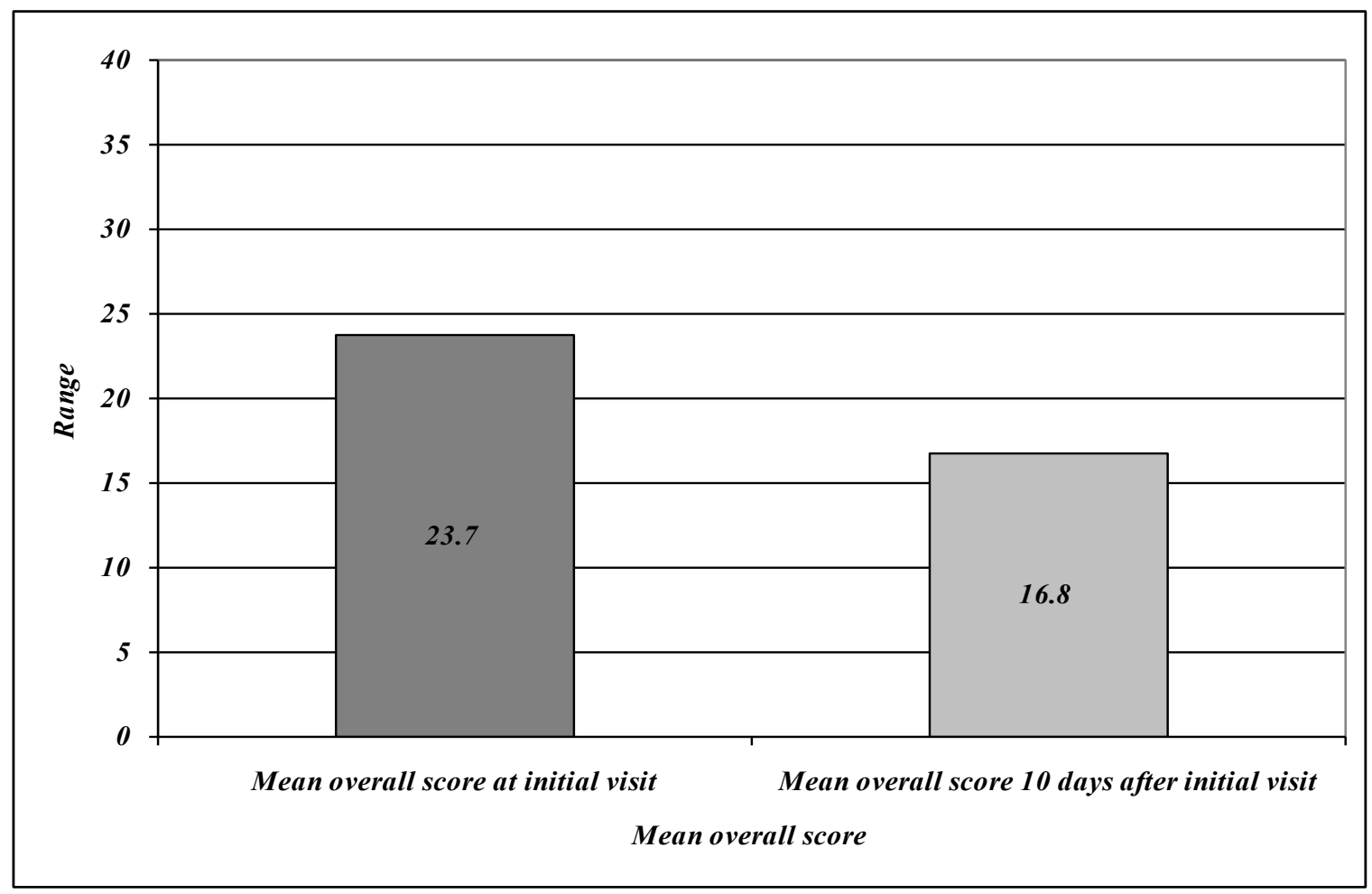

Fig. (2). Mean overall CAT scores at initial visit and 10 days after initial visit.

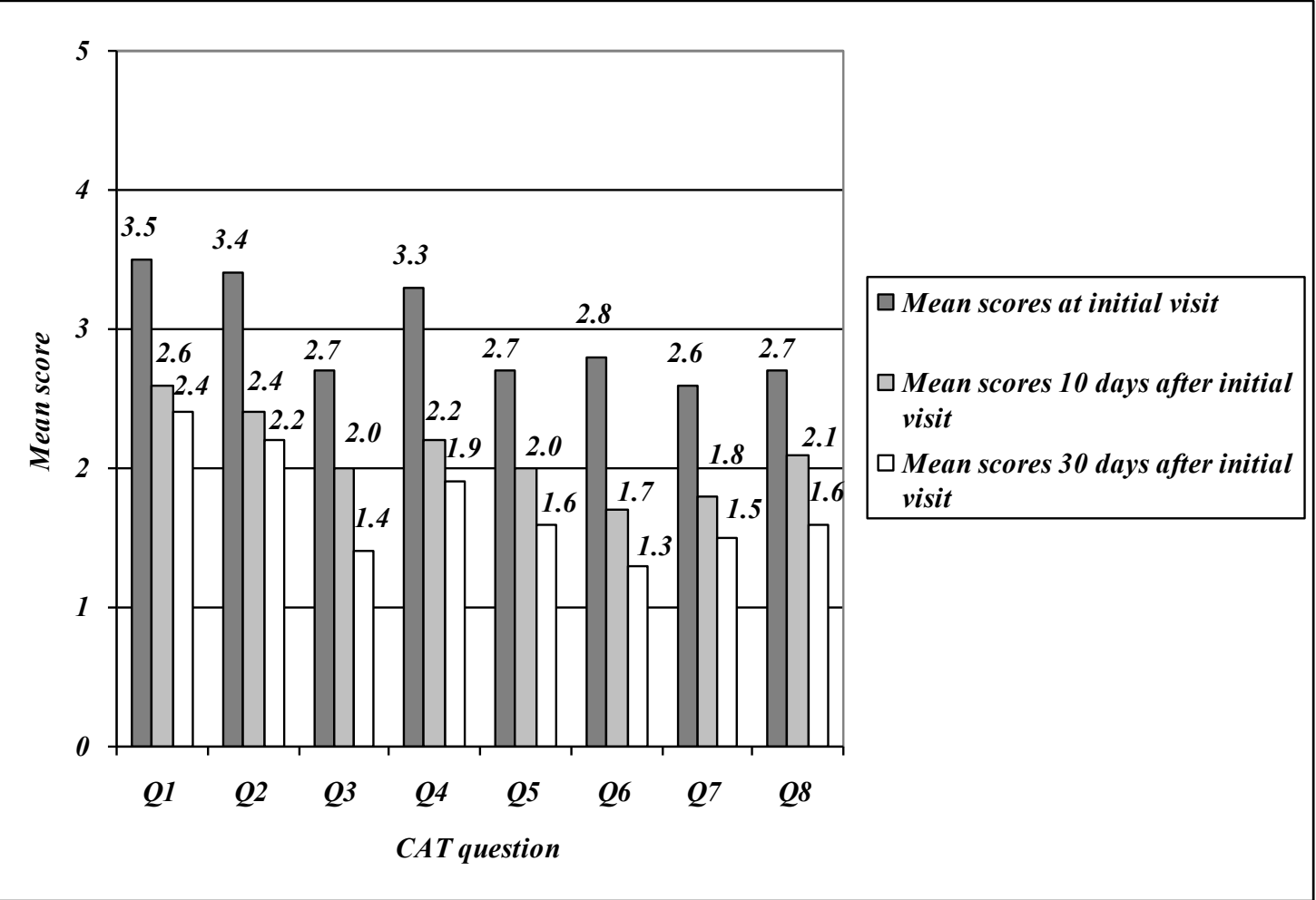

Fig. (3). Mean scores of the CAT questions at initial visit, 10 and 30 days after initial visit.

\section{DISCUSSION}

As in the past COPD was considered as a disease characterized by breathlessness, a simple measure of breathlessness, such as the Modified British Medical Council (mMRC) Questionnaire was used for symptoms assessment.
In the last years it has been recognized that COPD has multiple systematic effects requiring more comprehensive symptom assessment instead of measure of breathlessness [12]. In addition, several studies have indicated that the relationship between values of the lung function parameters 


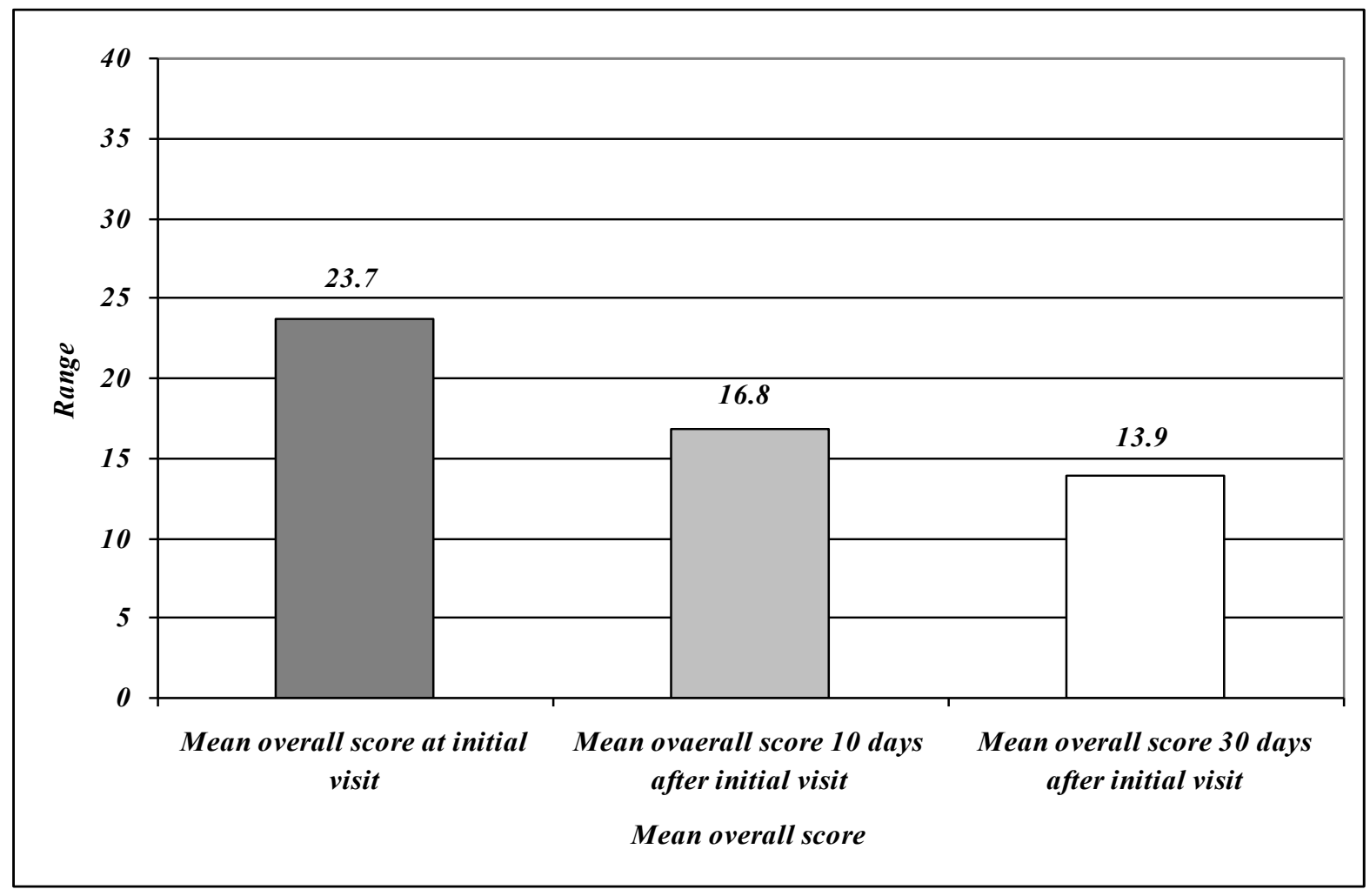

Fig. (4). Mean overall CAT scores at initial visit, 10 and 30 days after initial visit.

$\left(\mathrm{FEV}_{1}\right)$ and health status in patients with COPD generally is not strong $[12,13]$. As recognized by the GOLD strategic document, the health status, lung function and exacerbations frequency are complementary and all together define the severity of the COPD in a particular patient [2].

By time, it was considered that the most comprehensive questionnaires for assessment of health status in the patients with COPD, e.g. the St. George Respiratory Questionnaire (SGRQ) [14], are too complex for use in routine practice, so there was a need for developing of shorter questionnaires for multidimensional assessment of COPD which can be used in everyday work. The CAT and the CCQ [15] are short and easy-to-use in routine practice questionnaires developed in the last decade.

The CAT is a simple-to-complete tool which can measure the impact of COPD on the patient's health in order to manage optimally and to reduce the burden of the disease as much as possible. The development of the CAT has involved established methodologies used to develop psychometric tools [15]. It has been validated in prospective studies and their results have indicated that it can be used globally $[16,17]$.

So far, the usefulness of the CAT in assessment of the impact of COPD exacerbations on health status, as well as of the responding to the treatment and degree of recovery are evaluated in the process of the test validation $[18,19]$ and in a few studies [20-23]. Results from the assessment done in the process of validation indicate that a difference or change in the overall CAT score of 2 or more suggests a clinically significant difference or change in health status (Minimum Clinically Important Difference - MCID) [18]. On the other side, based on their own results, Tsiglianni et al. [20] estimated the CAT's MCID at 3,76 points. Results from the first validation study suggest that CAT scores in patients with moderate-severe exacerbations are approximately 5 units higher than in those who have stable COPD [16]. In this study patients who responded to the treatment for their exacerbation reduced their CAT score by 2 units in 14 days, whereas patients who did not respond to the treatment had no change in the score [19]. In addition, according to the results of the study performed by Mackay et al. [21], the CAT score has to improve by at least 5 units to consider that the patient has recovered from exacerbation.

In the present study we evaluated changes in the CAT scores in COPD patients with bacterial exacerbation diagnosed and treated in outpatient setting according to the actual recommendations. The CAT was completed by the same patients at initial visit (i.e. at the time when the exacerbation was diagnosed and the treatment began); 10 days after initial visit following the actual GOLD recommendations for the length of antibiotic therapy of 5 to 10 days [2], and 30 days after initial visit taking into account that recovery from exacerbation should last several weeks and some patients may never recover fully $[2,10]$.

The mean overall score at initial visit has value indicating high impact of COPD on patient's health status. The highest particular mean scores were registered for cough, phlegm and breathlessness at low level of physical effort that was expected as these symptom are considered as major symptoms of COPD exacerbation [2, 6]. We registered significant reduction of the mean scores of all eight CAT questions at the end of antibiotic therapy (i.e. 10 days after initial visit), that resulted in significant reduction of mean 
overall CAT score of 6.9 points. At the last visit (30 days after initial visit) we registered additional reduction of the mean scores of all eight questions and significant reduction of the mean overall CAT score of 2.9 points as compared to its value registered at the second visit. The reduction of the mean overall CAT score at the third visit as compared to its value at the first visit was 9.8 points.

Similar results were obtained in the multicentric study performed in Spain by Miravitlles et al. [23] aimed at assessment of the course of CAT and CCQ scores during recovery from exacerbations of COPD including 164 outpatients and 322 inpatients. In this study, at the time of exacerbation, the mean overall CAT score of the study participants was 22.0 (22.8 in inpatients and 20.4 in outpatients). After recovery, i.e. 4 to 6 weeks from initial visit, the authors found significant reduction of 9.9 points (8.9 in inpatients and 10.4 in outpatients).

The findings of this study are subjects of at least three limitations. Firstly, relatively small number of the study participants from one center could have certain implications on the data obtained and its interpretation. Secondly, we had no CAT scores of the same patients before the exacerbation occurred, so we could not compared them with CAT scores at the time of exacerbation and 30 days after its diagnosis and treatment. Currently, there is no well-established MCID for CAT, so the degree of impairment and recovery in our patients could not be compared with its acceptable value. The strength of the study is its observational design in a sample of outpatients with bacterial exacerbation of COPD evaluated in three time points of the course of the exacerbation.

\section{CONCLUSION}

In conclusion, in an observational, prospective study aimed at assessment of the course of CAT scores during bacterial exacerbations of COPD treated in outpatient setting, we found significant improvement in the patient's health status during recovery from exacerbation as compared to their health status at the time of exacerbation. Our findings confirm the CAT as a useful tool for the measurement of the health status during the exacerbation and for evaluation of recovery. In addition, there is a need of new studies in order to establish the role of the CAT in the managing of COPD exacerbations.

\section{ETHICAL APPROVAL}

The Ethical Committee of the Institute of Occupational Health of R. Macedonia, Skopje - WHO Collaborating Center and $\mathrm{GA}^{2} \mathrm{LEN}$ Collaborating Center gave approval for performing the study and publishing the results obtained (03273/06.2014).

\section{AUTHORS PARTICIPATIONS}

JM participated in the study design, data collection, managing the analyses of the study, and writing all versions of the manuscript. JKB participated in the study design, managing the analyses of the study, as well as writing all versions of the manuscript. KV performed the statistical analysis and participated in the managing of the analyses of the study. SS and DM participated in the data collection and in the managing of the analyses of the study. All authors read and approved the final manuscript.

\section{CONFLICT OF INTEREST}

The authors confirm that this article content has no conflict of interest.

\section{ACKNOWLEDGEMENTS}

Declared none.

\section{REFERENCES}

[1] European Respiratory Society. European Lung White Book: Huddersfield, European Respiratory Society Journals Ltd 2003.

[2] Global Strategy for the Diagnosis, Management, and Prevention of Chronic Obstructive Pulmonary Disease: 2014 Update. Available at: http://www.goldcopd.org/ (10.05.2014).

[3] Jones PW. COPD assessment test-rationale, development, validation and performance. J COPD 2013; 10(2): 269-71.

[4] Pasquale MK, Sun SX, Song F, Hartnett HJ, Stemkowski SA. Impact of exacerbations on health care cost and resource utilization in chronic obstructive pulmonary disease patients with chronic bronchitis from a predominantly Medicare population. Int $\mathrm{J}$ Chron Obstruct Pulmon Dis 2012; 7: 757-64.

[5] Ball P, Chodosh S, Grossman R, Tillotson G, Wilson R. Causes, epidemiology, and treatment of bronchial infections. Infect Med 2000; 17: 186-98.

[6] Anthonisen NR, Menfreda J, Warren CP, Herschfield EG, Harding HK, Nelson NA. Antibiotic therapy in exacerbations of chronic obstructive pulmonary disease. Ann Intern Med 1987; 106 (2): 196204.

[7] Woodhead M, Blasi F, Ewig S, et al. Guidelines for the management of adult lower respiratory tract infections. Eur Respir J 2005; 26: 1138-80.

[8] Celli BR, MacNee W. Standards for the diagnosis and treatment of patients with COPD: a summary of the ATS/ERS position paper. Eur Respir J 2004; 23 (6): 932-46.

[9] Hurst JR, Vestbo J, Anzueto A, et al. Susceptibility to exacerbation in chronic obstructive pulmonary disease. N Engl J Med 2010; 363: 1128-38.

[10] Hurst JR, Vestbo J, Anzueto A, et al. Susceptibility to exacerbation in chronic obstructive pulmonary disease. N Engl J Med 2010; 363 . $1128-38$

[11] COPD Assessment Test. Available at: www.catestonline.org (10 05.2014).

[12] Jones PW. Health status measurement in chronic obstructive pulmonary disease. Thorax 2001; 56: 880-7.

[13] Augusti A, Calverley PMA, Celi B, et al. Characterisation of COPD heterogeneity in the ECLIPSE cohort. Respir Res 2010; 11: 122.

[14] Jones PW, Quirk FH, Baveystock CM. Littlejohns P. A selfcomplete measure for chronic airflow limitation - the St George Respiratory Questionnaire. Am Rev Respir Dis 1992; 145: 132127.

[15] Reda AA, Kotz D, Kocks JW, Wesseling G, van Schayck CP. Reliability and validity of the clinical COPD questionnaire. Respir Med 2010; 104(11): 1675-82.

[16] Jones PW, Harding G, Berry P, Wiklund I, Chen W-H, Leidy NK Development and first validation of the COPD Assessment Test Eur Respir J 2009; 34: 648-54.

[17] Wiklund I, Berry P, Lu KX, Fang J, Fu C. The Chinese translation of COPD Assessment Test ${ }^{\mathrm{TM}}$ (CAT) provides valid and reliable measurement of COPD health status in Chinese COPD patients. Am J Respir Crit Care Med 2010; 181: A3575.

[18] Jones PW, Bruselle G, Dal Negro RW, et al. Properties of the COPD assessment test in a cross-sectional European study. Eur Respir J 2011; 38: 29-35.

[19] Jones PW, Harding G, Wiklund I, Berry P, Tabberer M, Yu R, Leidy NK. Tests of the responsiveness of the Chronic Obstructive Pulmonary Disease (COPD) Assessment Test ${ }^{\mathrm{TM}}$ (CAT) following 
acute exacerbations and pulmonary rehabilitation. Chest 2012; 142(1): 134-40.

[20] Tsiglianni IG, van der Molen T, Moraitaki D, et al. Assessing health status in COPD. A head-to-head comparison between the COPD assessment test 9CAT and the Clinical COPD questionnaire (CCQ). BMC Pulm Med 2012; 12: 20.

[21] Mackay AJ, Donaldson GC, Patel AR, Jones PW, Hurst JR, Wedzicha JA. Usefulness of the chronic obstructive pulmonary disease assessment test to evaluate severity of COPD exacerbations. Am J Respir Crit Care Med 2012; 185: 1218-24.
Feliz-Rodriguez D, Zudaire S, Carpio C, et al. Evolution of the COPD Assessment Test score during chronic obstructive pulmonary disease exacerbations: determinants and prognostic value. Can Respir J 2013; 20(5): 92-7.

[23] Miravitlles M, Garcia-Sidro P, Fernandez-Nistal A, Buendia MJ, de los Monteros MJE, Molina J. Course of COPD assessment test (CAT) and clinical COPD questionnaire (CCQ) scores during recovery from exacerbations of chronic obstructive pulmonary disease. Health Qual Life Outcomes 2013; 11: 147.

(C) Minov et al.; Licensee Bentham Open.

This is an open access article licensed under the terms of the Creative Commons Attribution Non-Commercial License (http://creativecommons.org/licenses/by-nc/3.0/) which permits unrestricted, non-commercial use, distribution and reproduction in any medium, provided the work is properly cited. 